\title{
Associations of personality traits and childhood insult experience with perceived husbands` psychological aggression among Iranian women
}

\begin{abstract}
Psychological aggression against wives is a social problem in all societies. To analyze possible predictive factors of psychological aggression against wives, this study examined 398 women selected through multi-stage stratified sampling techniques. Research participants responded to the Conflict Tactics Scale, questions about childhood insult experience, and the Five-Factor Personality Inventory (NEO-FFI). Results showed that $86 \%$ of respondents experienced psychological aggression from their husbands during the last year. Results also revealed that $46.7 \%$ and $43.3 \%$ of respondents were targets of insults during childhood by their mothers and fathers, respectively. Childhood insult experience and neuroticism, extraversion, agreeableness and conscientiousness personality traits predicted psychological aggression by husbands against their wives. Multinomial logistic regression revealed that neuroticism was a significant predictor of minor and severe psychological aggression against wives. The results highlighted the importance of childhood insult experience and personality traits in explaining the severity of psychological aggression against wives in Tehran, Iran.
\end{abstract}

Keyword: Personality traits; Childhood insult experience; Psychological aggression; CTS2; NEO-FFI; Logistic regression 